\title{
Biocompatibility and Effectiveness of a Novel, Organic Olive Oil-Based Denture Adhesive: A Multicenter Randomized and Placebo-Controlled Clinical Trial
}

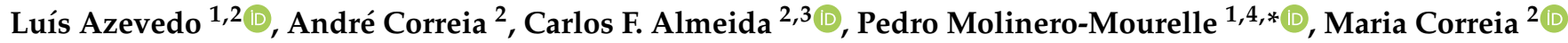 \\ and Jaime Del Río Highsmith ${ }^{1}$
}

Citation: Azevedo, L.; Correia, A.; Almeida, C.F.; Molinero-Mourelle, P.; Correia, M.; Del Río Highsmith, J. Biocompatibility and Effectiveness of a Novel, Organic Olive Oil-Based Denture Adhesive: A Multicenter Randomized and Placebo-Controlled Clinical Trial. Int. J. Environ. Res. Public Health 2021, 18, 3398. https:// doi.org/10.3390/ijerph18073398

Academic Editors: Katherine Chiu Man Leung and Chun Hung Chu

Received: 8 February 2021

Accepted: 22 March 2021

Published: 25 March 2021

Publisher's Note: MDPI stays neutral with regard to jurisdictional claims in published maps and institutional affiliations.

Copyright: (c) 2021 by the authors. Licensee MDPI, Basel, Switzerland. This article is an open access article distributed under the terms and conditions of the Creative Commons Attribution (CC BY) license (https:// creativecommons.org/licenses/by/ $4.0 /)$.
1 Department of Conservative Dentistry and Orofacial Prosthodontics, Faculty of Dentistry, Complutense University of Madrid, 28040 Madrid, Spain; lperei02@ucm.es (L.A.); jrh@odon.ucm.es (J.D.R.H.)

2 Centre for Interdisciplinary Research in Health, Faculty of Dental Medicine, Universidade Católica Portuguesa, 3504 Viseu, Portugal; andrecorreia@ucp.pt (A.C.); carloscenfa@gmail.com (C.F.A.); mcorreia@ucp.pt (M.C.)

3 Department of Oral Rehabilitation, Universidade do Porto, 4200 Oporto, Portugal

4 Department of Reconstructive Dentistry and Gerodontology, School of Dental Medicine, University of Bern, 3010 Bern, Switzerland

* Correspondence: pedromol@ucm.es; Tel.: +34-913-941-922
Abstract: To assess the clinical efficacy of a novel, organic olive oil-based denture adhesive and its effect on Candida albicans growth in maxillary edentulous individuals wearing complete dentures, individuals were selected from two dental schools in Portugal and Spain. Twenty-eight complete dentures were relined, following a standardized protocol. The novel product (test) was compared with a commercialized adhesive (control) and Vaseline (placebo) randomly assigned in a cross-study design. The retention resistance was measured with a gnathometer and a dynamometer. The patients related outcome evaluations with a five-point questionnaire, and the Candida albicans growth in a Sabouraud dextrose agar (SDA) medium was used to evaluate differences between the placebo and experimental product. Twenty-three participants were included. The dynamometer evaluation showed significant differences between not using a denture adhesive and using either (experimental, $p=0.03$; control, $p=0.04)$ and no significant differences between the two adhesives $(p>0.05)$. In the subjective analysis, the experimental adhesive showed a significantly longer effectiveness $(p=0.001)$, and the control reported better results in taste $(p=0.03)$ and in chewing $(p=0.001)$. The test adhesive showed better $(p<0.001)$ Candida albicans growth inhibition. The experimental adhesive showed longer effectiveness than the control and the placebo with a better inhibition capacity for the growth of Candida albicans. Patients reported better abilities for speech, chewing, taste, and retirement in the control adhesive.

Keywords: prosthodontics; edentulism; elderly; complete dentures; Candida albicans; antimicrobial activity

\section{Introduction}

Complete dentures continue to be a reliable treatment option for edentulous patients because of medical and economic constraints [1]. Dentures' retention, stability, and support depend on the intimate adaptation of their base to the soft and hard tissues, the peripheral seal fir, and saliva's presence between the dentures and the intraoral tissues [2,3]. However, in several clinical situations, saliva's natural adhesiveness and the denture base design and extension cannot provide enough stability and retention. In those cases, denture adhesives proved to be a good option for patients by increasing comfort levels and ultimately improving function performance $[4,5]$.

Effective action mechanisms of denture adhesives depend on the combination of physical and chemical forces [6]. When in contact with saliva, denture adhesives increase by 50 to $150 \%$ in volume, mainly because of some of their components' hydrophilic nature. They 
eliminate the empty spaces between the underlying oral mucosa and the dentures' base, and they ultimately improve the peripheral sealing and increase the dentures' stabilization and retention [6].

In the last decades, several studies have been published to determine the effectiveness of denture adhesives [2,7]. Regardless of the various methods used, most of the studies concluded that denture adhesives improve stability and retention and, therefore, contribute to greater user satisfaction and confidence [7-15].

Besides retention, another clinical issue that denture wearers often face is oral tissue infection. Candida albicans is a commensal organism in the oral cavity of $45-65 \%$ of healthy individuals [16,17]. In denture wearers, the prevalence of Candida increases from 60 to $100 \%[16,18]$. Several studies have investigated denture adhesives' effect on oral microbiota but with contradictory results. One study [19] showed that Candida albicans growth in vitro was potentiated by some denture adhesives, whereas, in another study [20], denture adhesives showed antifungal behavior $[19,20]$.

Organic oils, including olive oil, have been known for their antioxidant, anti-antioxidant, anti-inflammatory, and antimicrobial properties [21] and have been used in dermatological products for some time [22]. However, proper testing in formulation for oral products has only recently been tested and demonstrated both for caries [23] and surgical and periodontal applications [24].

This clinical study aimed to assess the efficacy of a novel, organic olive oil-based denture adhesive in maxillary edentulous patients wearing complete dentures. Patientcentered outcomes associated with denture adhesive use, such as perceived degree of retention, patient satisfaction, and time of effectiveness were evaluated, as well as the growth of Candida albicans in vitro in the presence of both denture adhesives. The null hypothesis was that there were no statistically significant differences between the novel adhesive (test), the conventional adhesive (control), and the placebo adhesive for the clinical outcomes (retention, patient satisfaction, time of effectiveness) and for the Candida albicans growth.

\section{Materials and Methods}

\subsection{Study Design}

A randomized controlled clinical trial was designed following The Consolidated Standards of Reporting Trials (CONSORT) guidelines [25] and performed at the Department of Prosthodontics of the Faculty of Dentistry of the Complutense University of Madrid and at the Oral Rehabilitation Unit of the Faculty of Dental Medicine of the Portuguese Catholic University. The protocol was evaluated and approved by the research ethics committee of the Clinic San Carlos Hospital of Madrid, Spain (trial registration code: CEIC 18/515-R_P) following the Declaration of Helsinki's ethical principles for medical research involving human subjects. Informed consent was obtained from all participants before conducting the research.

\subsection{Study Participants}

The sample size was calculated based on the expected effect for the control adhesive [10], using an alpha value of 0.05 and a statistical power of $80 \%$ (G-Power v. 3.1.9.2, Dusseldorf, Germany). Patients were selected from a convenience sample at the Department of Prosthodontics of the Complutense University of Madrid's Faculty of Dentistry and at the Oral Rehabilitation Unit of the Portuguese Catholic University's Faculty of Dental Medicine.

Inclusion criteria were as follows: participants older than 18 years, fully edentulous for at least one year, maxillary dentures fabricated within the previous two years, availability for the study appointments, and confirmed absence of allergic sensitivity to the denture adhesive components. Patients with poor oral hygiene and patients incapable of clear communication because of neurological diseases or temporomandibular disorders were excluded from this study. 


\subsection{Study Intervention}

The dentures were clinically relined with a hard-reline resin material (Ufi Gel hard C, VOCO, Cuxhaven, Germany) according to the manufacturer's protocol. The same type of teeth was used for all dentures (SR Orthotyp PE for posterior teeth and SR Vivadent PE for anterior teeth, Ivoclar Vivadent, Lichtenstein) to ensure similar contact/wear. A bilateral balanced occlusal scheme was ensured and verified in all participants. Once relined, dentures were assessed for accuracy and correct adjustment. Participants were asked to wear them for two weeks to allow dentures to adjust and achieve a good fit. After this period, participants entered the experimental part of the study if no mucosa lesion was found.

\subsection{Experimental Design}

An international multicenter crossover, randomized, triple-blinded (the random assignment of denture adhesives and placebo in forms A, B, and C was not known by the investigator, the patient, and the statistical) clinical trial with a 2-week clearance period was adopted. After a 2-week adaptation period with the relined dentures, participants had a baseline-recording visit. During this appointment, initial retention values were registered using a gnathometer and a dynamometer. The initial participant-centered outcomes were also recorded in a questionnaire.

Participants were randomly assigned through Microsoft Excel 2010 software (Microsoft Co., Redmond, WA, USA) for one of the test products. Participants were instructed on the use of the test products (amount, application, and cleaning process) and were asked to use them in the following two weeks.

At the 2-week evaluation visit, the same outcomes measurements were registered, and participants completed another questionnaire. After this visit, participants were instructed to continue using their dentures for the following two weeks without using any product (clearance period). After this period, participants were again asked to use a new assigned product for another two weeks, and similar baseline and 2-week evaluations were made. Once each participant had completed the study using the three products, the visits scheme was repeated.

\subsection{Study Materials}

- Control adhesive (A): conventional denture adhesive, (Kukident Pro ${ }^{\circledR}$, Procter and Gamble, Cincinnati, OH, USA) cream form, composed of Polyvinyl Alcohol-Methyl acrylicate (PVM/MA) copolymers, liquid paraffin, sodium celluloses, petrol, colorings, preservatives, and aromatic particles.

- $\quad$ Experimental denture adhesive (B): novel adhesive, (OlivaFix ${ }^{\circledR}$ Gold, Bonyf AG, Lichtenstein) cream formulated with $30 \%$ extra virgin organic olive oil, with no zinc, mineral oil, or Vaseline.

- $\quad$ Placebo adhesive (C): Vaseline (Vaseline, Senti $2^{\circledR}$, Madrid, Spain).

The three tested adhesives were blinded and transferred into identical containers labeled A, B, and C for further assessment. For the clinical evaluation of the dentures' stability and retention, a disposable gnathometer (Procter and Gamble Co., Cincinnati, OH, USA) and a dynamometer (Correx, Haag-Streit, Bern, Switzerland) were used.

A gnathometer measures the occlusal force required to dislodge a complete denture when both arches occlude simultaneously. The participant bites until the denture moves and the indicator records it on a decimal scale from 0 to 10 units (gnathometer units). When the result of the measurement was between two units the lowest was registered. The measurements were repeated three times, with a one-minute interval, in three locations: the incisors and between the left and right first molars. The mean value of these measurements was used for analysis.

A dynamometer quantitatively measures (grams (g)) the force necessary to dislodge the denture from the residual ridge of the patient when traction is applied. Three records 
were made first in the anterior area of the frenulum and then in the posterior lateral areas. The mean value of these measurements was used for the analysis.

\subsection{Outcome Variables}

The main assessed variables were the dentures' retention and stability, measured using the gnathometer and the dynamometer, as described above. The participant-centered outcomes were recorded using a questionnaire. This questionnaire evaluated, on a scale of five items (very good, good, moderate, minimal, or very bad), the participant's subjective evaluation of the following variables: retention and stability, taste and consistency of the denture adhesive, denture adhesive intra-oral removal capacity, and the participant's willing to use the denture adhesive again. The clinical protocol and the questionnaire were adapted from Pradíes et al. [10].

\subsection{Pilot Study-Inter-and Intra-Observer Reliability}

A pilot clinical study was performed to determine the intra-observer measurement variability. Five participants with complete maxillary dentures were selected from each faculty. Participants had a natural dentition, a fixed prosthesis, or a removable prosthesis (on teeth or implants) in the antagonist arch. For each participant, the primary evaluator made six measurements (three with the dynamometer and three with the gnathometer only in the anterior area) with a one-minute break. One week later, at the same period of the day, the measurements were repeated for each participant with the same gnathometer. The measurement deviation was calculated using the Dahlberg formula, and the Pearson correlation was calculated as the reliability coefficient.

Another pilot study was carried out in the Faculty of Dental Medicine clinic of the Portuguese Catholic University to determine the interobserver concordance. Two main evaluators used the same gnathometer and dynamometer to obtain the corresponding measurements in all participants. They made three measurements in the anterior area, and the average value was used in the analysis. All measurements were made after a one-minute break to allow the participant to restore the denture comfortably. A three-way analysis of variance (ANOVA) was applied to assess the observers' influence due to the possible learning effect, while correcting patient results. The measurement error was calculated by the Dahlberg formula, and the concordance coefficient was calculated by the Pearson correlation.

\subsection{Effect of Denture Adhesives on Candida Albicans Growth}

In vitro evaluation of the effect of denture adhesives on the growth of Candida albicans ATCC 11225 was evaluated on solid Sabouraud dextrose media, following protocols similar to those used by Sampaio-Maia et al. [17]. Saturated solutions of the denture adhesives (1\% $w / v)$ were prepared in sterile saline solution $(0.9 \% \mathrm{NaCl})$ and added to a sterile Sabouraud dextrose agar (SDA). Thereafter, each plate $(20 \mathrm{~mL})$ of SDA received $1 \mathrm{~mL}$ of denture adhesive solution and was inoculated in triplicate with $0.5 \mathrm{~mL}$ of a standardized inoculum of $1 \times 10^{6}$ cells $/ \mathrm{mL}$ of Candida albicans ATCC11225 and incubated at $25^{\circ} \mathrm{C}$ for a week. The plates were observed in three moments, at 48,120 , and $168 \mathrm{~h}$, and the colony forming units (CFUs) were counted.

\subsection{Statistically Data Analysis}

Collected data were transferred to a database (Microsoft Excel, Microsoft, Redmond, WA, USA) and analyzed by two independent researchers. Subsequently, data were statistically processed with SPSS (SPSS for Windows, version 25, SPSS Inc., Chicago, IL, USA). For each test, normality was verified with Kolmogorov-Smirnov and Shapiro-Wilk statistical tests. For quantitative questions, the Kruskal-Wallis test was used to analyze possible differences between the test products in the absence of normality. In case of discrepancies, the Mann-Whitney test was applied to each product's results separately and the Bonferroni correction to a combination of the two. When normality was verified, an ANOVA was 
used, as well as the post-hoc Bonferroni test. The qualitative questions were expressed in percentages and with a chi-square test.

Results of the in vitro analysis were expressed in CFU/milliliter, corresponding to cells/milliliter. All measurements were obtained in triplicate, and all tests were repeated once. Means were calculated, and results were compared with a Student's $t$-test or with an ANOVA analysis. For all tests, $\alpha=0.05$ was used, and $p$-values equal to or less than 0.05 $(p \leq 0.05)$ were considered statistically significant.

\section{Results}

\subsection{In Vivo Assessment}

Thirty-two patients were recruited to participate in this study and 28 participants were finally included: 12 (42.86\%) in the Complutense University of Madrid and 16 (57.14\%) in the Universidade Católica Portuguesa. Five (17.86\%) individuals did not complete the experimental part of the study and were not considered in the evaluation. The remaining participants $(n=23)$ completed the study (Figure 1$)$.

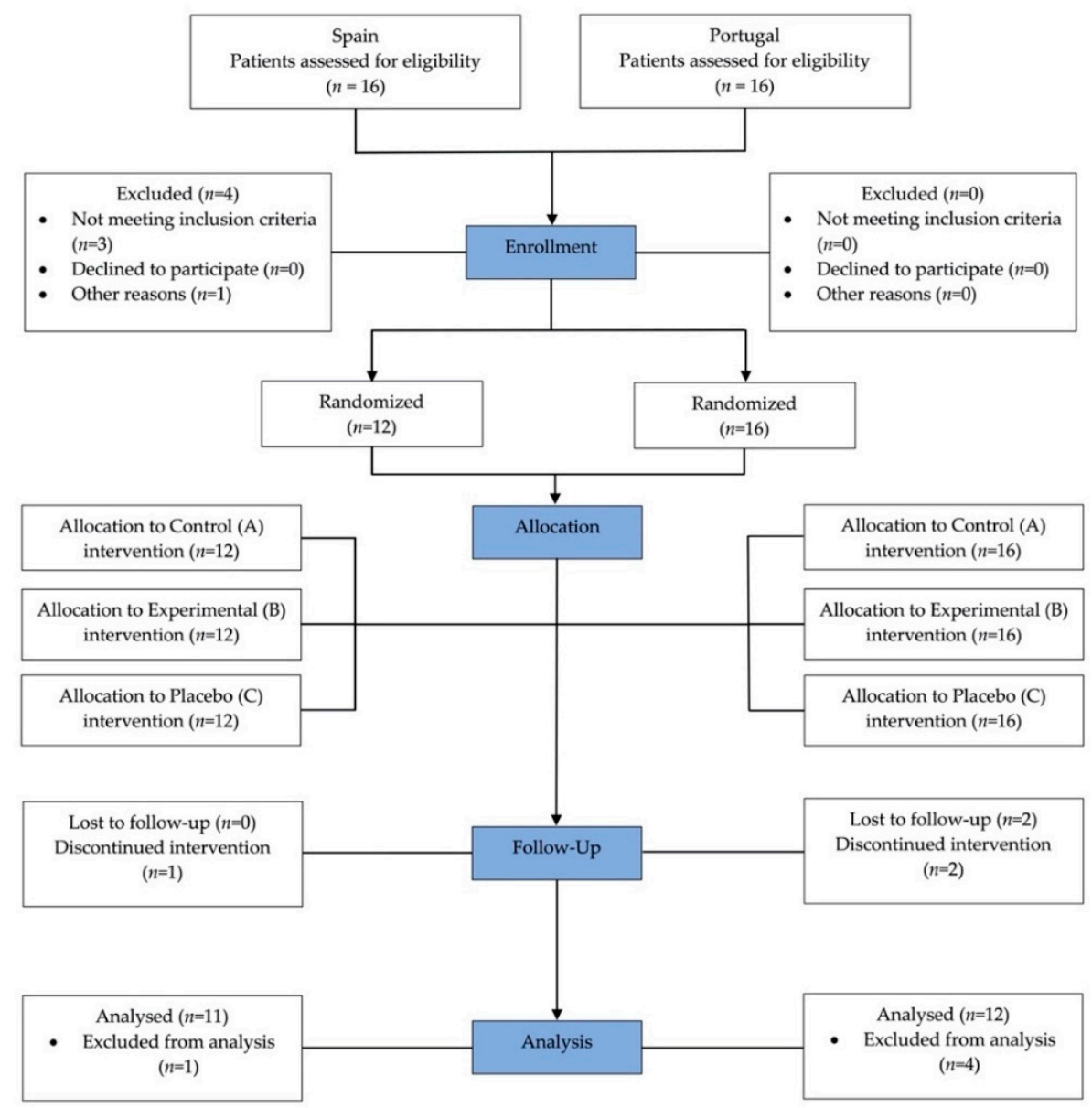

Figure 1. Flowchart diagram of the study protocol according to The Consolidated Standards of Reporting Trials (CONSORT) guidelines [25].

Most of the participants were older than 65 years (y) old ( $n=15 ; 65.20 \%$; (45-89); mean: $68 \mathrm{y})$ and female $(n=15 ; 65.22 \%)$. The average age of their current dentures was 1.57 years, with a range between one $(n=10 ; 43.5 \%)$ and two years $(n=13 ; 56.5 \%)$. Regarding the frequency of denture's hygiene, although the clear majority of individuals did clean their denture at least twice a day $(n=15 ; 65.2 \%), 30.4 \%(n=7)$ did it only once a day, and $4.3 \%$ $(n=1)$ did not clean them. The $69.6 \%(n=16)$ of the sample reported having already used denture adhesives before, however, $62.5 \%(n=10)$ had stopped using them, reporting a bad taste $(n=2 ; 8.7 \%)$ and ineffectiveness $(n=4 ; 17.4 \%)$ as the main causes. 
Based on the questionnaire responses, the participant-centered outcomes reported that the experimental denture adhesive had longer effectiveness, which, for $73.91 \%(n=17)$ of the sample, was greater than $8 \mathrm{~h}(p=0.0001)$. The control adhesive presented better results, improving the speaking $(p=0.003)$ and chewing ability $(p=0.001)$ and facilitating the removal/cleaning of the adhesive from the denture $(p=0.003)$, with statistically significant differences (Tables 1 and 2).

There were no statistically significant differences between the three products in the subjective evaluation of the dentures' retention and stability. The overall intra-observer measurement error was 0.15 gnathometer units, whereas the overall interobserver measurement error was 0.12 gnathometer units. The intra-observer reliability coefficient was 0.90 , whereas the overall interobserver reliability coefficient was $0.60 \mathrm{~g}$ for the dynamometer and $0.80 \mathrm{~g}$ for the gnathometer. The ANOVA showed no systematic observer effect in the evaluations with the dynamometer $(p=0.178)$ and the gnathometer $(p=0.78)$.

According to Table 3, the mean force needed to dislodge the dentures, measured with a dynamometer, was about $155.8 \pm 51.5 \mathrm{~g}$ when the experimental denture adhesive was used and was $152.7 \pm 52.6 \mathrm{~g}$ with the control denture adhesive. Although the force required to dislodge the dentures with the experimental denture adhesive was more significant than that required with the control denture adhesive, that difference was not statistically significant $(p>0.05)$. The results of the gnathometer measurements (Table 3) revealed that when the experimental denture adhesive was used the necessary force was about $1.0 \pm 0.6$ units and when the control denture adhesive was used it was $1.1 \pm 0.6$. There were no statistically significant differences between the three groups $(p=0.055)$.

\subsection{In Vitro Assessment}

The effect of the denture adhesives on the SDA is shown in Figure 2; after $48 \mathrm{~h}$, there was no growth of Candida albicans ATCC 11225 in the presence of the denture adhesives. However, after five days, there was growth with both. The experimental adhesive had a higher impact on inhibiting the growth of Candida albicans ATCC 11225 by showing a significant difference $(p<0.05)$ in the number of CFUs five and seven days after the test compared to the control adhesive and the control (Candida albicans with no product). Although there was some growth of Candida albicans ATCC 11225 in the presence of the two denture adhesives (experimental and control), the growth was slower and less intense with the experimental denture adhesive.

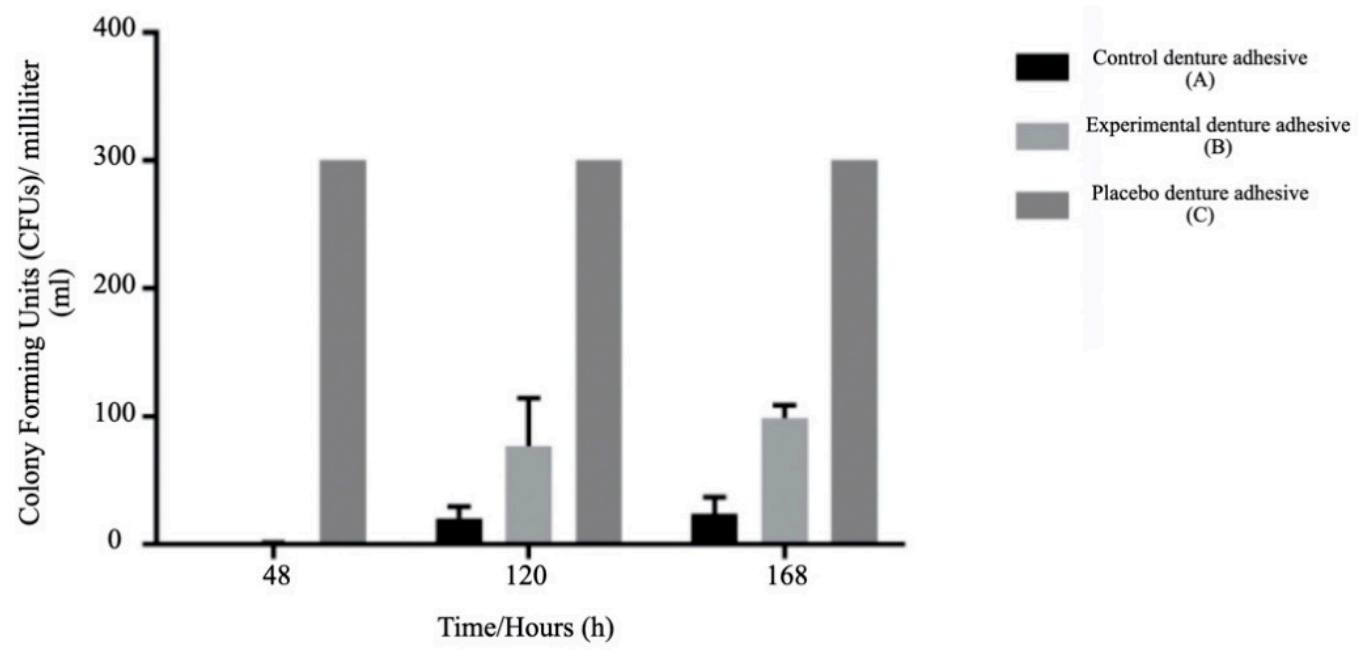

Figure 2. Effect of the denture adhesives on the growth of Candida albicans ATCC 11225 in the Sabouraud dextrose agar (SDA) medium. 
Table 1. Descriptive analysis of the patient-centered outcomes.

\begin{tabular}{|c|c|c|c|c|c|c|c|c|c|c|c|c|c|c|c|c|c|c|c|}
\hline \multirow{2}{*}{$\begin{array}{c}\text { Participant-Centered } \\
\text { Outcomes Concerning } \\
\text { Denture Adhesives }\end{array}$} & \multicolumn{2}{|c|}{$\begin{array}{c}\text { Speaking } \\
\text { Improvement }\end{array}$} & \multicolumn{2}{|c|}{$\begin{array}{l}\text { Chewing } \\
\text { Ability }\end{array}$} & \multicolumn{4}{|c|}{ Satisfaction Degree } & \multicolumn{2}{|c|}{ Taste } & \multicolumn{4}{|c|}{ Effectiveness Time } & \multicolumn{3}{|c|}{ Opinion on Utility } & \multicolumn{2}{|c|}{ Cleaning/Removal } \\
\hline & Yes & No & Yes & No & No & Little & Sufficient & Very & Yes & No & $\begin{array}{l}\text { Less } \\
\text { than } 4 \mathrm{~h}\end{array}$ & $4-8 \mathrm{~h}$ & $8-12 \mathrm{~h}$ & $\begin{array}{c}\text { More } \\
\text { than } 12 \mathrm{~h}\end{array}$ & Zero & Little & Effective & Easy & Difficult \\
\hline $\begin{array}{l}\text { Experimental denture } \\
\text { adhesive (B) }\end{array}$ & $\begin{array}{l}65.22 \% \\
(15)\end{array}$ & $\begin{array}{l}34.78 \% \\
(8)\end{array}$ & $\begin{array}{l}56.52 \% \\
(13)\end{array}$ & $\begin{array}{l}43.48 \% \\
(10)\end{array}$ & $\begin{array}{l}8.70 \% \\
(2)\end{array}$ & $\begin{array}{l}47.83 \% \\
(11)\end{array}$ & $\begin{array}{l}39.13 \% \\
\quad(9)\end{array}$ & $\begin{array}{l}8.70 \% \\
(2)\end{array}$ & $\begin{array}{l}91.30 \% \\
(21)\end{array}$ & $\begin{array}{l}56.52 \% \\
(13)\end{array}$ & $\begin{array}{l}43.48 \% \\
(10)\end{array}$ & $\begin{array}{l}8.70 \% \\
(2)\end{array}$ & $\begin{array}{l}17.39 \% \\
(4)\end{array}$ & $\begin{array}{l}73.91 \% \\
(17)\end{array}$ & $\begin{array}{l}0.00 \% \\
(0)\end{array}$ & $\begin{array}{l}8.70 \% \\
(2)\end{array}$ & $\begin{array}{l}47.83 \% \\
(11)\end{array}$ & $\begin{array}{l}39.13 \% \\
(9)\end{array}$ & $\begin{array}{l}65.22 \% \\
(15)\end{array}$ \\
\hline $\begin{array}{l}\text { Placebo denture } \\
\text { adhesive }(C)\end{array}$ & $\begin{array}{l}26.98 \% \\
(6)\end{array}$ & $\begin{array}{l}73.91 \% \\
(17)\end{array}$ & $\begin{array}{l}21.74 \% \\
(5)\end{array}$ & $\begin{array}{l}78.26 \% \\
(18)\end{array}$ & $\begin{array}{l}21.74 \% \\
(5)\end{array}$ & $\begin{array}{l}52.17 \% \\
(12)\end{array}$ & $\begin{array}{l}26.09 \% \\
(6)\end{array}$ & $\begin{array}{l}21.74 \% \\
(5)\end{array}$ & $\begin{array}{l}60.87 \% \\
(14)\end{array}$ & $\begin{array}{l}39.13 \% \\
(9)\end{array}$ & $\begin{array}{l}39.13 \% \\
(9)\end{array}$ & $\begin{array}{l}78.26 \% \\
(18)\end{array}$ & $\begin{array}{l}13.04 \% \\
\text { (3) }\end{array}$ & $\begin{array}{l}8.70 \% \\
(2)\end{array}$ & $\begin{array}{l}0.00 \% \\
(0)\end{array}$ & $\begin{array}{l}21.74 \% \\
(5)\end{array}$ & $\begin{array}{l}52.17 \% \\
(12)\end{array}$ & $\begin{array}{l}26.09 \% \\
(6)\end{array}$ & $\begin{array}{l}8.70 \% \\
(2)\end{array}$ \\
\hline
\end{tabular}

Table 2. Inferential analysis of the patient-centered outcomes.

\begin{tabular}{|c|c|c|c|c|c|c|}
\hline \multirow{2}{*}{ Participant-Centered Outcomes Concerning Denture Adhesives } & Speaking Improvement & Chewing Ability & Satisfaction Degree & Taste & Effectiveness Time & Cleaning/Removal \\
\hline & $p$ & $p$ & $p$ & $p$ & $p$ & $p$ \\
\hline Control denture adhesive (A) vs placebo denture adhesive (C) & 0.004 & 0.001 & 0.024 & 0.009 & 0.001 & 0.01 \\
\hline Control denture adhesive (A) vs experimental denture adhesive (B) & 0.003 & 0.001 & 0.073 & 0.027 & 0.001 & 0.026 \\
\hline Experimental denture adhesive (B) vs placebo denture adhesive (C) & 0.004 & 0.001 & 0.09 & 0.365 & 0.001 & 0.037 \\
\hline
\end{tabular}


Table 3. Dynamometer and gnathometer measurements.

\begin{tabular}{|c|c|c|c|c|}
\hline \multirow{2}{*}{ Groups } & \multicolumn{2}{|c|}{ Dynamometer } & \multicolumn{2}{|c|}{ Gnathometer } \\
\hline & Mean \pm SD (g) & $p$-Value & Mean \pm SD & $p$-Value \\
\hline $\begin{array}{l}\text { No denture } \\
\text { adhesive }\end{array}$ & $123.8 \pm 38.3$ & $\begin{array}{l}\text { vs }(B)-\mathbf{0 . 0 3 4} \\
\text { vs }(A)-\mathbf{0 . 0 4 1} \\
\text { vs }(C)-1.000\end{array}$ & $0.8 \pm 0.6$ & \\
\hline $\begin{array}{l}\text { Control denture } \\
\text { adhesive }(\mathrm{A})\end{array}$ & $152.7 \pm 52.6$ & $\begin{array}{c}\text { vs initial-0.041 } \\
\text { vs }(B)-0.995 \\
\text { vs }(\mathrm{C})-\mathbf{0 . 0 4 8}\end{array}$ & $1.1 \pm 0.6$ & 0.055 \\
\hline $\begin{array}{c}\text { Experimental } \\
\text { denture adhesive (B) }\end{array}$ & $155.8 \pm 51.5$ & $\begin{array}{l}\text { vs initial-0.034 } \\
\text { vs }(\mathrm{A})-0.995 \\
\text { vs }(\mathrm{C})-\mathbf{0 . 0 4 7}\end{array}$ & $1 \pm 0.6$ & \\
\hline $\begin{array}{l}\text { Placebo denture } \\
\text { adhesive }(C)\end{array}$ & $122.7 \pm 36.0$ & $\begin{array}{l}\text { vs initial-1.000 } \\
\text { vs }(\mathrm{B})-\mathbf{0 . 0 4 7} \\
\text { vs }(\mathrm{A})-\mathbf{0 . 0 4 8}\end{array}$ & $0.8 \pm 0.5$ & \\
\hline
\end{tabular}

\section{Discussion}

The null hypothesis was rejected since significant differences were found between the assessed adhesives. The present study selected dentures with a maximum wearing period of two years according to Maeda et al. [26]; a denture needs to be relined after approximately 27 months. The ideal protocol would be the evaluation of new dentures, as in other studies $[10,27]$. Nevertheless, considering the short evaluation period of our research, and the fact that dentures require an adaptation period, a bias could occur. Therefore, we decided that the best method would be to fit and reline the dentures with a hard reline, and then verify that they all had a correct bilateral, balanced occlusion. The present study was a phase IV clinical trial in which a new product (OlivaFix ${ }^{\circledR}$ Gold) was evaluated and compared with a previously studied product (Kukident Pro ${ }^{\circledR}$ ) and a placebo $\left(\right.$ Vaseline $\left.{ }^{\circledR}\right)$. Vaseline was selected as the placebo because of its consistency, similar to denture adhesives, and its lack of a specific flavor.

This study was designed as a multicenter to evaluate these products more efficiently by obtaining a good sample of participants to satisfy the study's objective within a reasonable time frame. A pre-team meeting was held to standardize the procedures as much as possible, and a pilot study was conducted to standardize and calibrate the clinical evaluators. All procedures were recorded in video format in case there were doubts.

Regarding the influence of the products on chewing improvement, the control denture adhesive presented better results $(p=0.001)$ than the experimental denture adhesive. These denture adhesives were significantly better than the placebo $(p=0.001)$ for both. These results agree with several studies $[14,28,29]$, which found that denture adhesives led to an increase in the chewing rate and a decrease in the duration of chewing cycles. Although the differences between the two denture adhesives were significant, in descriptive terms, the number of participants who stated that their chewing improved with the control denture adhesive was not much higher than those for the experimental denture adhesive $(n=16$; $69.57 \%$ vs. $n=13 ; 56.52 \%$ ).

In terms of effectiveness time, the experimental denture adhesive had significantly longer effectiveness than the control $(p<0.0001)$. Its composition may explain these results. The experimental adhesive features an innovative formula using a high concentration of olive oil instead of commonly used ingredients, such as zinc and petrolatum. Scientific evidence indicates that denture adhesive's retention force decreases over time [28] because of its dissolution [30]. As explained above, when the adhesive is in contact with saliva, it slowly absorbs water and increases in volume, increasing in viscosity until the hydrophilic polymer particles come into contact with each other to form a continuous polymer matrix. Subsequently, oral fluids destroy the polymer matrix, decreasing the viscosity and resulting in progressively weaker bond strength. Therefore, the olive oil, which is highly viscous, 
in the experimental denture adhesive composition, may explain the significantly longer adhesion effectiveness.

In this research, two quantitative variables were combined. First, by using a dynamometer, we tried to simulate participants' force when speaking, smiling, and doing other daily activities. Then, with the gnathometer, the objective was to simulate movements that occur during chewing. Thus, the combination of these evaluation methods allowed us to test a wide variety of movements that can influence the stability of complete dentures. However, it should be noticed that the evaluated forces do not consider the frequency, duration, and magnitude of the functional or parafunctional forces carried out on a daily routine. The average value of the tensile force required to dislocate the denture when using the denture adhesives was approximately $150 \mathrm{~g}$. These results are lower than those reported in other studies [10,31], which ranged from $350 \mathrm{~g}$ to $1095 \mathrm{~g}$. However, Pradíes et al. [10] evaluated new dentures, which may justify that observation. Nonetheless, if we analyze the scientific evidence regarding implant-retained overdentures, retention values were found between approximately 350 and $500 \mathrm{~N}$, according to the different retention systems used [32,33]. Thus, the values obtained with denture adhesives would not be those expected in the overdentures with ball retention systems, for example.

Finally, regarding the gnathometer values, in general, the results indicated similar mean values for the two denture adhesives. Additionally, the reported values with the use of denture adhesives were higher than those obtained without these products. However, according to inferential analysis, there were no significant differences between the three products. Other authors obtained average values much higher than ours $[2,11,27]$. On the other hand, the results obtained by Pradíes et al. [10], with and without denture adhesives, are in agreement with ours. If we do not consider units and focus only on the percentage of increase or improvement with the use of denture adhesives compared to the use of none (37.5\%), our study also agrees with that of Polyzois et al. [11] (32.5\%) on the evaluation of some denture adhesives.

When interpreting these results, it should be borne in mind that most of the studies, except for the study by Pradíes et al. [10], only obtained measurements from the anterior zone. In contrast, in our study, the evaluations were performed in three locations (two posterior and one anterior), and the average value was calculated; this may justify the discrepancies obtained.

Regarding the inhibition of Candida albicans growth, although there was a fungal growth in the presence of the two denture adhesives (experimental and control), the experimental denture adhesive had a greater effect on inhibiting that growth, with statistically significant differences at days five and seven of the trial. We could expect better results with the control denture adhesive because it has zinc, which is known to have antifungal activity [34]. However, the experimental denture adhesive, which has no zinc in its composition, showed a more significant antifungal effect. This effect may be due to the organic olive oil in the experimental denture adhesive, which is known to have phenolic components that have anti-inflammatory and even anti-cancer properties [35]. Dacrory et al. evaluated the use of olive oil by-products in a new antimicrobial hydrogel [35]. They discovered that this product has an antimicrobial capacity against Staphylococcus aureus, Pseudomonas aeruginosa, and Candida albicans [36]. Therefore, although the experimental denture adhesive does not contain zinc (a classic antimicrobial) in its composition, the presence of these possible by-products of the organic olive oil may be responsible for the antifungal effect it had in this study.

A limitation of the laboratory evaluation is that in vitro observations are not always representative of the in vivo situation. Saliva components and salivary flow and variable intraoral $\mathrm{pH}$ can interfere with the growth of Candida albicans. Furthermore, since there is an association between oral streptococci and Candida albicans [37], it would also be essential to test the denture adhesives' effect on the growth of oral streptococci.

Further multicenter, international studies are needed to assess the differences and similarities between countries regarding denture adhesives. In addition, educational pro- 
grams for patients regarding this issue should be developed. Feedback and comments from participants can be valuable to the manufacturers of these products, thus improving several less successful aspects. It would also be important to develop guidelines or protocols regarding denture adhesives.

\section{Conclusions}

Within the limitations previously discussed, the following conclusions can be drawn:

- There were no differences in the force required to dislodge the denture under traction between the experimental and the control denture adhesives.

- Differences in individuals' evaluation of the dentures' retention and stability were not statistically significant among the three products.

- The experimental adhesive showed a better effectiveness time than the control and placebo.

- The control denture adhesive improved the ability to speak and chew, taste and odor, and ease of removal with significant differences.

- The experimental denture adhesive showed the best antimycotic effect against the growth of Candida albicans compared to the control and placebo.

Author Contributions: Conceptualization, methodology, software, and validation were performed by L.A., A.C., M.C. and J.D.R.H.; data curation, writing-original draft preparation and writingreview and editing were performed by L.A., C.F.A. and P.M.-M.; visualization, supervision, project administration, and funding acquisition were performed by A.C., M.C. and J.D.R.H. All authors have read and agreed to the published version of the manuscript.

Funding: Bonyf S.A. partially funded this research through article 83 of the Spanish Universities Organic Law (18/515-R_P). A.C. and M.C. were financially supported in part through the Center for Interdisciplinary Research in Health (UIDB/04279/2020 and UIDP/04279/2020).

Institutional Review Board Statement: The protocol was evaluated and approved by the Research Ethics Committee of the Clínico San Carlos Hospital of Madrid, Spain (trial registration code CEIC 18/515-R_P) following the Declaration of Helsinki's ethical principles for medical research involving human subjects.

Informed Consent Statement: Informed consent was obtained from all subjects involved in the study. Written informed consent was obtained from the patients to publish this paper.

Data Availability Statement: The data that support the findings of this study are available from the corresponding author, P.M.-M., upon reasonable request.

Acknowledgments: The authors would like to thank Isabel González Moya for her assistance in this study.

Conflicts of Interest: The authors declare no conflict of interest. The funders had no role in the study's design; in the collection, analyses, or interpretation of data; in the writing of the manuscript, or in the decision to publish the results.

\section{References}

1. Thalji, G.; McGraw, K.; Cooper, L.F. Maxillary Complete Denture Outcomes: A Systematic Review of Patient-Based Outcomes. Int. J. Oral Maxillofac. Implants 2016, 31, 169-181. [CrossRef] [PubMed]

2. De Baat, C.; Van't Hof, M.; Van Zeghbroeck, L.; Özcan, M.; Kalk, W. An international multicenter study on the effectiveness of a denture adhesive in maxillary dentures using disposable gnathometers. Clin. Oral Investig. 2007, 11, 237-243. [CrossRef]

3. De Oliveira Junior, N.M.; Rodriguez, L.S.; Marin, D.O.M.; Paleari, A.G.; Pero, A.C.; Compagnoni, M.A. Masticatory performance of complete denture wearers after using two adhesives: A crossover randomized clinical trial. J. Prosthet. Dent. 2014, 112, 1182-1187. [CrossRef]

4. Coates, A.J. Usage of denture adhesives. J. Dent. 2000, 28, 137-140. [CrossRef]

5. Uysal, H.; Altay, O.T.; Alparslan, N.; Bilge, A. Comparison of four different denture cushion adhesives-a subjective study. J. Oral Rehabil. 1998, 25, 209-213. [CrossRef] [PubMed]

6. Shay, K. Denture hygiene: A review and update. J. Contemp. Dent Pract. 2000, 1, 1-8. [CrossRef]

7. Tarbet, W.J.; Grossman, E. Observations of denture-supporting tissue during six months of denture adhesive wearing. J. Am. Dent Assoc. 1980, 101, 789-791. [CrossRef] [PubMed]

8. Berg, E. A clinical comparison of four denture adhesives. Int. J. Prosthodont. 1991, 4, 449-456. 
9. Grasso, J.; Gay, T.; Rendell, J.; Baker, R.; Knippernberg, S.; Finkeldey, J.; Zou, X.; Winston, J.L. Effect of denture adhesive on retention of the mandibular and maxillary dentures during function. J. Clin. Dent. 2000, 11, 98-103.

10. Pradies, G.; Sanz, I.; Evans, O.; Martinez, F.; Sanz, M. Clinical study comparing the efficacy of two denture adhesives in complete denture patients. Int. J. Prosthodont. 2009, 22, 361-367.

11. Polyzois, G.; Lagouvardos, P.; Frangou, M.; Stefaniotis, T. Efficacy of denture adhesives in maxillary dentures using gnathodynamometry: A comparative study. Odontology 2011, 99, 155-161. [CrossRef] [PubMed]

12. Polyzois, G.L.; De Baat, C. Attitudes and usage of denture adhesives by complete denture wearers: A survey in Greece and the Netherlands. Gerodontology 2012, 29, e807-e814. [CrossRef]

13. Koronis, S.; Pizatos, E.; Polyzois, G.; Lagouvardos, P. Clinical evaluation of three denture cushion adhesives by complete denture wearers. Gerodontology 2012, 29, e161-e169. [CrossRef]

14. Goncalves, T.M.S.V.; Viu, F.C.; Goncalves, L.M.; Garcia, R.C.M.R. Denture adhesives improve mastication in denture wearers. Int. J. Prosthodont. 2014, 27, 140-146. [CrossRef] [PubMed]

15. Pachore, N.J.; Patel, J.R.; Sethuraman, R.; Naveen, Y.G. A comparative analysis of the effect of three types of denture adhesives on the retention of maxillary denture bases: An in vivo study. J. Indian Prosthodont. Soc. 2014, 14, 369-375. [CrossRef]

16. Oliveira, M.C.; Oliveira, V.M.; Vieira, A.C.; Rambob, I. In vivo assessment of the effect of an adhesive for complete dentures on colonisation of Candida species. Gerodontology 2010, 27, 303-307. [CrossRef]

17. Sampaio-Maia, B.; Figueiral, M.H.; Sousa-Rodrigues, P.; Fernandes, M.H.; Scully, C. The effect of denture adhesives on Candida albicans growth in vitro. Gerodontology 2012, 29, e348-e356. [CrossRef] [PubMed]

18. Budtz-Jorgensen, E.; Stenderup, A.; Grabowski, M. An epidemiologic study of yeasts in elderly denture wearers. Commun. Dent. Oral Epidemiol. 1975, 3, 115-119. [CrossRef] [PubMed]

19. Stafford, G.D.; Russell, C. Efficiency of denture adhesives and their possible influence on oral microorganisms. J. Dent. Res. 1971, 50, 832-836. [CrossRef]

20. Makihira, S.; Nikawa, H.; Satonobu, S.V.; Jin, C.; Hamada, T. Growth of Candida species on commercial denture adhesives in vitro. Int. J. Prosthodont. 2001, 14, 48-52.

21. Jimenez-Lopez, C.; Carpena, M.; Lourenço-Lopes, C.; Gallardo-Gomez, M.; Lorenzo, J.M.; Barba, F.J.; Prieto, M.A.; Simal-Gandara, J. Bioactive Compounds and Quality of Extra Virgin Olive Oil. Foods 2020, 9, 1014.

22. Mota, A.H.; Silva, C.O.; Nicolai, M.; Baby, A.; Palma, L.; Rijo, P.; Ascensão, L.; Reis, C.P. Design and evaluation of novel topical formulation with olive oil as natural functional active. Pharm. Dev. Technol. 2018, 23, 794-805.

23. Nardi, G.M.; Fais, S.; Casu, C.; Mazur, M.; Di Giorgio, R.; Grassi, R.; Grassi, F.R.; Orrù, G. Mouthwash Based on Ozonated Olive Oil in Caries Prevention: A Preliminary In-Vitro Study. Int. J. Environ. Res. Public Health 2020, 17, 9106. [CrossRef] [PubMed]

24. Kaplan, V.; Hasanoglu Erbasar, G.N.; Cigerim, L.; Altay Turgut, H.; Cerit, A. Effect of St. John's wort oil and olive oil on the postoperative complications after third molar surgery: Randomized, double-blind clinical trial. Clin. Oral Investig. 2021, 25, 2429-2438. [CrossRef] [PubMed]

25. Schulz, K.F.; Altman, D.G.; Moher, D.; Group, C. CONSORT 2010 statement: Updated guidelines for reporting parallel group randomized trials. BMC Med. 2010, 8, 18. [CrossRef] [PubMed]

26. Maeda, Y.; Yang, T.-C.; Ikebe, K.; Andoh, T. Frequency of relining procedures during the maintenance period of removable prostheses: An experiential report. Int. J. Prosthodont. 2014, 27, 151-152. [CrossRef] [PubMed]

27. Ozcan, M.; Kulak, Y.; de Baat, C.; Arikan, A.; Ucankale, M. The effect of a new denture adhesive on bite force until denture dislodgement. J Prosthodont. 2005, 14, 122-126. [CrossRef] [PubMed]

28. Rendell, J.K.; Gay, T.; Grasso, J.E.; Baker, R.A.; Winston, J.L. The effect of denture adhesive on mandibular movement during chewing. J. Am. Dent. Assoc. 2000, 131, 981-986. [CrossRef]

29. Fujimori, T.; Hirano, S.; Hayakawa, I. Effects of a denture adhesive on masticatory functions for complete denture wearersConsideration for the condition of denture-bearing tissues. J. Med. Dent. Sci. 2002, 49, 151-156.

30. Fløystrand, F.; Koppang, R.; Williams, V.D.; Ørstavik, J. A method for testing denture adhesives. J. Prosthet. Dent. 1991, 66, 501-504. [CrossRef]

31. Mañes, J.F.; Selva, E.J.; De-Barutell, A.; Bouazza, K. Comparison of the retention strengths of three complete denture adhesives: An in vivo study. Med. Oral Patol. Oral Cir. Bucal. 2011, 16, e132-e136. [CrossRef] [PubMed]

32. Chung, K.-H.; Chung, C.-Y.; Cagna, D.R.; Cronin, R.J.J. Retention characteristics of attachment systems for implant overdentures. J. Prosthodont. 2004, 13, 221-226. [CrossRef]

33. Bayer, S.; Steinheuser, D.; Gruner, M.; Keilig, L.; Enkling, N.; Stark, H.; Mues, S. Comparative study of four retentive anchor systems for implant supported overdentures-Retention force changes. Gerodontology 2009, 26, 268-272. [CrossRef] [PubMed]

34. Mastrolorenzo, A.; Scozzafava, A.; Supuran, C.T. Antifungal activity of silver and zinc complexes of sulfadrug derivatives incorporating arylsulfonylureido moieties. Eur. J. Pharm. Sci. 2000, 11, 99-107. [CrossRef]

35. Ververis, K.; Karagiannis, T.C. Mechanisms of action of phenolic compounds in olive. J. Diet Suppl. $2012,9,96-109$.

36. Dacrory, S.; Abou-Yousef, H.; Abouzeid, R.E.; Kamel, S.; Abdel-Aziz, M.S.; El-Badry, M. Antimicrobial cellulosic hydrogel from olive oil industrial residue. Int. J. Biol. Macromol. 2018, 117, 179-188. [CrossRef]

37. Souza, J.G.S.; Bertolini, M.; Thompson, A.; Barão, V.A.R.; Dongari-Bagtzoglou, A. Biofilm Interactions of Candida albicans and Mitis Group Streptococci in a Titanium-Mucosal Interface Model. Appl. Environ. Microbiol. 2020, 86, e02950-19. [CrossRef] [PubMed] 